\title{
Seguimiento de egresados, telebachillerato comunitario Campeche. Estudio de caso
}

\author{
Follow-up of Graduates, Campeche Community Telebachillerato \\ Case study
}

Acompanhamento de egressos da faculdade comunitária do Campeche. Estudo de caso

\author{
Thelma Núñez Amaro \\ Telebachillerato Comunitario, Campeche \\ thelma28na@gmail.com \\ https://orcid.org/0000-0002-9944-8686
}

\section{Resumen}

El presente documento contiene los resultados obtenidos de un estudio de seguimiento de egresados del servicio educativo telebachillerato comunitario del estado de Campeche, el cual se llevó a cabo con el propósito de valorar la pertinencia del servicio mediante el análisis de la trayectoria de sus egresados y el tránsito que han tenido al nivel superior . La metodología que se ha seleccionado fue el estudio de casos múltiples, con un enfoque cualitativo y un alcance descriptivo. Para ello se consideraron 516 egresados de las generaciones 2013-2016, 2014-2017, 2015-2018 y 2016-2019 de los 19 planteles que conforman el servicio educativo. Los resultados muestran que han egresado durante las cuatro generaciones 516 jóvenes, de los cuales 279 son hombres y 237 mujeres; asimismo, 139 egresados se encuentran estudiando, lo que corresponde a $26.93 \%$ del total. Este dato es particularmente importante por la necesidad de facilitar el tránsito a nivel superior. Igualmente, se registró que 316 egresados se encuentran laborando en actividades diferentes a su formación profesional (es decir, desarrollo comunitario), pues principalmente realizan labores del campo, del hogar o trabajan de forma independiente. 


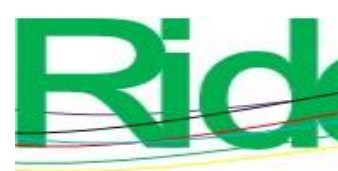

Revista Iberoamericana para la
Investigación y el Desarrollo Educativo
ISSN $2007-7467$

Los resultados obtenidos plasman la necesidad de establecer mecanismos para fortalecer la formación integral que reciben para incidir positivamente en su comunidad y para transitar al nivel superior de forma satisfactoria.

Palabras clave: evaluación de la educación, educación media superior, pertinencia.

\section{Abstract}

This document contains the results obtained from a Follow-up Study of Graduates of the Community Telebachillerato Educational Service of the State of Campeche, which was carried out with the purpose of evaluating the relevance of the educational service, this by analyzing the trajectory of their graduates and the transit they have had at the Higher Level. The methodology that has been selected is the Multiple Case Study, with a qualitative approach and a descriptive scope. For this, 516 graduates of the 2013-2016, 2014-2017, 2015-2018, 2016-2019 generations were considered; of the 19 schools that make up the educational service.

The results show that 516 young people have graduated during the 4 generations, of whom 279 are men and 237 women, and 139 graduates are studying, which corresponds to $26.93 \%$ of the total graduates. This is particularly important due to the need to facilitate transit at a higher level. It was also recorded that 316 graduates are working in activities other than their professional training Community Development; They mainly carry out work in the fields, household chores and work independently. The results obtained reflect the need to establish mechanisms to strengthen the comprehensive training they receive that allows them, on the one hand, to have a positive impact on their community and, on the other hand, to successfully move to the Higher Level.

Keywords: educational evaluation, upper middle education, relevance. 


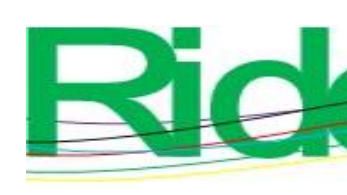

Revista Iberoamericana para la
Investigación y el Desarrollo Educativo
ISSN $2007-7467$

\section{Resumo}

Este documento contém os resultados obtidos em estudo de acompanhamento com egressos do serviço de telebachillerato comunitário educacional do estado de Campeche, realizado com o objetivo de avaliar a relevância do serviço por meio da análise da trajetória de seus egressos e do tráfego que eles tiveram para o nível superior. A metodologia escolhida foi o estudo de casos múltiplos, com abordagem qualitativa e âmbito descritivo. Para isso, foram considerados 516 egressos das gerações 2013-2016, 2014-2017, 2015-2018 e 2016-2019 das 19 escolas que compõem o serviço educacional. Os resultados mostram que 516 jovens se formaram nas quatro gerações, sendo 279 homens e 237 mulheres; da mesma forma, estão estudando 139 egressos, o que corresponde a 26,93\% do total. Esses dados são particularmente importantes devido à necessidade de facilitar o trânsito para um nível superior. Da mesma forma, constatou-se que 316 egressos exercem atividades distintas da formação profissional (ou seja, desenvolvimento comunitário), uma vez que atuam principalmente no campo, em casa ou por conta própria.

Os resultados obtidos refletem a necessidade de se estabelecer mecanismos que fortaleçam a formação integral que recebem para impactar positivamente sua comunidade e passar de forma satisfatória para o nível superior.

Palavras-chave: avaliação educacional, ensino médio, relevância.

Fecha Recepción: Julio 2020

Fecha Aceptación: Enero 2021

\section{Introducción}

La educación media superior ha permitido que muchos jóvenes puedan acceder a una formación que los dote de competencias para desenvolverse en la vida y para continuar en el nivel superior. Sin embargo, dada la desigualdad existente en el país, es preciso reconocer los principales retos y dificultades que se deben enfrentar:

Si bien los diagnósticos en ese nivel muestran alguna (leve) mejoría, nos revelan altos índices de deserción de sus alumnos; bajo rendimiento escolar; poco interés por las materias y la forma en que se imparten; baja formación magisterial y desprotección laboral (una porción elevada de profesores lo son de asignatura); así como desatención de autoridades, personal docente y padres de familia respecto del entorno en que estos jóvenes realizan sus estudios, que los puede convertir consumo de drogas, relaciones sexuales 


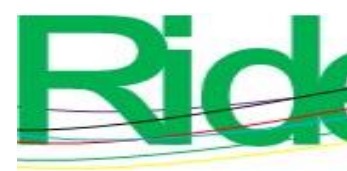

Revista Iberoamericana para la Investigación y el Desarrollo Educativo ISSN 2007 - 7467

desprotegidas y violencia en general (Instituto Nacional para la Evaluación de la Educación [INEE], 2018a, p. 5).

Por ese motivo, en el presente documento - como parte del Congreso Nacional de Investigación Educativa (COMIE) — se presentan los resultados de un estudio de caso de alta eficacia escolar realizado en un plantel de telebachillerato comunitario de Aguascalientes. En primera instancia se plasman las problemáticas principales de la educación media superior, es decir, "falta de equidad en la oferta educativa, carencias en la formación tanto de profesores como de directivos de los distintos subsistemas, bajos resultados educativos, insuficiencia de infraestructura y equipamiento de las escuelas, falta de articulación con la demanda laboral (Ramírez y Padilla González, 2017, p. 2).

En este contexto, el Servicio Educativo Telebachillerato Comunitario (TBC) se concreta tomando en cuenta la reforma institucional que obliga a prestar el servicio de educación media superior, el cual establece su obligatoriedad para la población de entre 16 y 17 años de edad; ante esta situación, el Gobierno federal, en el sexenio 2013-2018, se propuso ampliar la cobertura hasta $80 \%$.

El TBC imparte educación media superior con el fin de formar personas que puedan desarrollar habilidades mediante la realización de diversos tipos de proyectos recreativos, sociales, culturales, ambientales, económicos, artísticos, científicos, etc., los cuales se vinculan a las competencias establecidas en el perfil de egreso. Asimismo, tienen incidencia directa en la comunidad, dado su propósito formativo estipulado en el documento base: "Dotar a las y los jóvenes de una formación integral conformada por habilidades, conocimientos y actitudes que les permita comprender la cultura de su tiempo y actuar como sujetos activos capaces de influir positivamente en contextos locales y globales" (Subsecretaría de Educación Media Superior [SEMS], 2018, p. 5).

Durante el ciclo escolar 2017-2018, según cifras obtenidas del archivo histórico del INEE (2018b), en el estado de Campeche funcionan 125 planteles de educación media superior que incluyen bachillerato general, bachillerato tecnológico, profesional técnico. Con 19 planteles educativos (lo que constituye a $15.2 \%$ del total de planteles), el telebachillerato comunitario es el segundo servicio educativo más grande en el estado. En la tabla 1 se enseñan las cifras de educación media superior en el estado de Campeche para el inicio del ciclo escolar 2017-2018: 


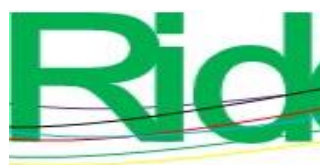

Revista Iberoamericana para la Investigación y el Desarrollo Educativo ISSN 2007 - 7467

Tabla 1. Cifras de educación media superior en el estado de Campeche (inicio del ciclo escolar 2017-2018)

\begin{tabular}{|c|c|c|c|c|c|c|c|c|c|}
\hline \multirow[b]{2}{*}{$\begin{array}{l}\text { Sostenimi } \\
\text { ento }\end{array}$} & \multirow{2}{*}{$\begin{array}{l}\text { Control } \\
\text { administrat } \\
\text { ivo }\end{array}$} & \multirow[b]{2}{*}{ Institución } & \multirow[b]{2}{*}{$\begin{array}{l}\text { Tipo de } \\
\text { plantel }\end{array}$} & \multicolumn{2}{|c|}{ Alumnos } & \multicolumn{2}{|c|}{ Docentes } & \multicolumn{2}{|c|}{ Planteles } \\
\hline & & & & Abs & $\%$ & $\begin{array}{l}\mathrm{Ab} \\
\mathrm{s} .\end{array}$ & $\%$ & $\begin{array}{l}\mathrm{Ab} \\
\mathrm{S} .\end{array}$ & $\%$ \\
\hline \multirow[t]{4}{*}{ Federal } & \multirow{3}{*}{$\begin{array}{l}\text { Centralizad } \\
\text { o }\end{array}$} & \multirow{3}{*}{$\begin{array}{l}\text { Coordinada } \\
\text { s por } \\
\text { SEMS }\end{array}$} & DGB & 360 & 1.0 & 16 & 0.8 & 1 & 0.8 \\
\hline & & & $\begin{array}{l}\text { UEMSTAy } \\
\text { CM }\end{array}$ & $\begin{array}{l}435 \\
6\end{array}$ & $\begin{array}{l}11 . \\
9\end{array}$ & $\begin{array}{l}23 \\
6\end{array}$ & $\begin{array}{l}11 . \\
3\end{array}$ & 6 & 4.8 \\
\hline & & & UEMSTIS & $\begin{array}{l}436 \\
1\end{array}$ & $\begin{array}{l}11 . \\
9\end{array}$ & $\begin{array}{l}18 \\
4\end{array}$ & 8.8 & 4 & 3.2 \\
\hline & \multicolumn{3}{|l|}{ Total } & $\begin{array}{l}907 \\
7\end{array}$ & $\begin{array}{l}24 . \\
8\end{array}$ & $\begin{array}{l}43 \\
6 \\
\end{array}$ & $\begin{array}{l}20 . \\
9\end{array}$ & 11 & 8.8 \\
\hline \multirow[t]{7}{*}{ Estatal } & $\begin{array}{l}\text { Centralizad } \\
\text { o }\end{array}$ & $\begin{array}{l}\text { Organismo } \\
\text { centralizad } \\
\text { os de los } \\
\text { estados }\end{array}$ & $\begin{array}{l}\text { Bachillerat } \\
\text { os estatales }\end{array}$ & $\begin{array}{l}170 \\
4\end{array}$ & 4.7 & $\begin{array}{l}11 \\
5\end{array}$ & 5.5 & 3 & 2.4 \\
\hline & \multirow[t]{5}{*}{$\begin{array}{l}\text { Descentrali } \\
\text { zado }\end{array}$} & \multirow{5}{*}{$\begin{array}{l}\text { Organismo } \\
\text { s } \\
\text { descentraliz } \\
\text { ados de los } \\
\text { estados }\end{array}$} & CECyTE & $\begin{array}{l}502 \\
3 \\
\end{array}$ & $\begin{array}{l}13 . \\
7\end{array}$ & $\begin{array}{l}18 \\
1 \\
\end{array}$ & 8.7 & 7 & 5.6 \\
\hline & & & CONALEP & $\begin{array}{l}180 \\
9\end{array}$ & 4.9 & $\begin{array}{l}10 \\
5\end{array}$ & 5.0 & 3 & 2.4 \\
\hline & & & $\begin{array}{l}\text { Colegio de } \\
\text { Bachilleres }\end{array}$ & $\begin{array}{l}768 \\
4 \\
\end{array}$ & $\begin{array}{l}21 . \\
0\end{array}$ & $\begin{array}{l}32 \\
4 \\
\end{array}$ & $\begin{array}{l}15 . \\
5\end{array}$ & 20 & $\begin{array}{l}16 . \\
0\end{array}$ \\
\hline & & & $\begin{array}{l}\text { Educación } \\
\text { Media } \\
\text { Superior a } \\
\text { Distancia }\end{array}$ & $\begin{array}{l}253 \\
4\end{array}$ & 6.9 & $\begin{array}{l}11 \\
3\end{array}$ & 5.4 & 17 & $\begin{array}{l}13 . \\
6\end{array}$ \\
\hline & & & $\begin{array}{l}\text { Telebachill } \\
\text { erato } \\
\text { Comunitari } \\
\text { o }\end{array}$ & 835 & 2.3 & 57 & 2.7 & 19 & $\begin{array}{l}15 . \\
2\end{array}$ \\
\hline & \multicolumn{3}{|l|}{ Total } & $\begin{array}{l}195 \\
89 \\
\end{array}$ & $\begin{array}{l}53 . \\
5\end{array}$ & $\begin{array}{l}89 \\
5 \\
\end{array}$ & $\begin{array}{l}42 . \\
9\end{array}$ & 69 & $\begin{array}{l}55 . \\
2\end{array}$ \\
\hline \multirow[t]{5}{*}{$\begin{array}{l}\text { Autónom } \\
\text { o }\end{array}$} & Autónomo & $\begin{array}{l}\text { Universida } \\
\text { des } \\
\text { Autónomas } \\
\text { Estatales }\end{array}$ & $\begin{array}{l}\text { Bachilllerat } \\
\text { os } \\
\text { Autónomos }\end{array}$ & $\begin{array}{l}507 \\
3\end{array}$ & $\begin{array}{l}13 . \\
9\end{array}$ & $\begin{array}{l}22 \\
4\end{array}$ & $\begin{array}{l}10 . \\
7\end{array}$ & 4 & 3.2 \\
\hline & \multicolumn{3}{|l|}{ Total } & $\begin{array}{l}507 \\
3 \\
\end{array}$ & $\begin{array}{l}13 . \\
9\end{array}$ & \begin{tabular}{|l|}
22 \\
4 \\
\end{tabular} & $\begin{array}{l}10 . \\
7\end{array}$ & 4 & 3.2 \\
\hline & Particular & $\begin{array}{l}\text { Institucione } \\
\mathrm{S} \\
\text { particulares }\end{array}$ & $\begin{array}{l}\text { Bachillerat } \\
\text { os } \\
\text { particulares }\end{array}$ & $\begin{array}{l}286 \\
5\end{array}$ & 7.8 & $\begin{array}{l}52 \\
5\end{array}$ & $\begin{array}{l}25 . \\
1\end{array}$ & 40 & $\begin{array}{l}32 . \\
0\end{array}$ \\
\hline & Subsidiado & $\begin{array}{l}\text { Subsidiado } \\
\text { s por los } \\
\text { estados o } \\
\text { AC }\end{array}$ & $\begin{array}{l}\text { Preparatori } \\
\text { a Estatal o } \\
\text { Federal por } \\
\text { Cooperació } \\
\text { n }\end{array}$ & 9 & 0.0 & 8 & 0.4 & 1 & 0.8 \\
\hline & \multicolumn{3}{|l|}{ Total } & $\begin{array}{l}287 \\
4\end{array}$ & 7.8 & \begin{tabular}{|l|}
$\mathbf{5 3}$ \\
$\mathbf{3}$ \\
\end{tabular} & $\begin{array}{l}25 . \\
5\end{array}$ & 41 & $\begin{array}{l}32 . \\
8\end{array}$ \\
\hline
\end{tabular}




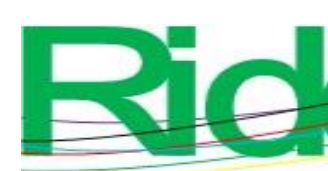

Total

Revista Iberoamericana para la Investigación y el Desarrollo Educativo ISSN $2007-7467$

\begin{tabular}{|l|l|l|l|l|l|l|}
\hline Total & $\mathbf{3 6 6}$ & $\mathbf{1 0 0}$ & $\mathbf{2 0}$ & $\mathbf{1 0 0}$ & $\mathbf{1 2}$ & $\mathbf{1 0 0}$ \\
& $\mathbf{1 3}$ & $\mathbf{. 0}$ & $\mathbf{8 8}$ & $\mathbf{. 0}$ & $\mathbf{5}$ & $\mathbf{. 0}$ \\
\hline
\end{tabular}

Fuente: INEE (2018b)

Para el año 2019, luego de seis años de iniciar operaciones y con cuatro generaciones de egresados, se hace necesario reconocer la ruta que han seguido los graduados del TBC y en qué medida se ha cumplido el propósito formativo, cómo ha sido la experiencia del estudiante y cuál ha sido el aporte social y la incidencia en la comunidad. Este trabajo, por tanto, procura valorar la pertinencia del servicio educativo reconociendo la ruta profesional y laboral que han seguido sus egresados.

Uno de los aspectos más importantes en la evaluación del servicio educativo es el referido a los programas de estudio, los cuales deben responder a las necesidades actuales. En palabras de Barriga, González, Pacheco Pinzón, Saad Dayan y Rojas Drummond (1990), eso implica "la necesidad de adecuar de manera permanente el plan curricular, determinar sus logros, para ello es necesario evaluar continuamente los aspectos interno y externos del currículo" (p. 133).

Ahora bien, para Barriga et al. (1990) evaluar la efectividad del currículo contempla los siguientes aspectos:

1. Análisis de los egresados y sus funciones profesionales. Con este análisis se busca determinar qué tipo de funciones profesionales desempeñan realmente los egresados, si se capacitaron para estas funciones o no en la carrera, qué utilidad reportan los egresados, empleadores y beneficiarios de dichas funciones, qué funciones se consideran convenientes para integrarse al plan de estudios.

2. Análisis de los egresados y de los mercados de trabajo. Es indispensable determinar los tipos de áreas y sectores en que los egresados están trabajando, analizar si corresponden a mercados de trabajo tradicionales, novedosos o potenciales, investigar los índices de desempleo y subempleo de los egresados, obtener una relación de empleo en comparación con egresados de otras instituciones.

3. Análisis de la labor del egresado a partir de su intervención en la solución real de necesidades sociales y los problemas de la comunidad para los que fue diseñada la carrera. En este punto se confrontará con la realidad para descubrir si realmente hay o no un vínculo estrecho entre las instituciones 


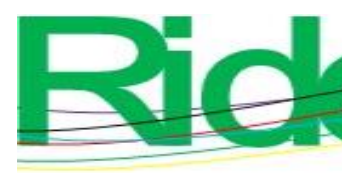

Revista Iberoamericana para la
Investigación y el Desarrollo Educativo
ISSN $2007-7467$

educativas y el sistema social, y se podrán reestructurar o cambiar los fundamentos, que son la parte medular del currículo (p. 147).

Desconocer la ocupación de los egresados del TBC limita las posibilidades para evaluar los programas de estudio, deja al servicio educativo sin insumos para mejorar la calidad de la educación impartida y, por tanto, no se puede incidir favorablemente en las comunidades rurales aledañas. Por ello, en este trabajo se ha planteado la siguiente pregunta de investigación: ¿cuál es la trayectoria que han seguido los egresados del telebachillerato comunitario en el estado de Campeche?

\section{Desarrollo}

La apertura de planteles de TBC en el estado de Campeche inició en 2013 con cuatro centros educativos en las comunidades de Cumpich, Mancolona, Oxcabal y Pablo García. Con un crecimiento paulatino cada año, en 2014 se abrieron cinco centros educativos más en las comunidades de Chunchintok, Chunkanán, Laguna Grande, Tikinmul y Suctuc. En 2015 se sumaron los centros de Isla Arena, La Victoria y Miguel Colorado.

Luego, en el año 2016 se abrieron seis planteles en las comunidades de Adolfo Ruiz Cortínez, Carlos Salinas de Gortari, Gustavo Díaz Ordaz, Nayarit de Castellot, San José de las Montañas y Yohaltun. Finalmente, en 2017 se abrió el centro educativo en Iturbide. Actualmente, se cuenta con 19 planteles en el interior del estado.

Este servicio tiene una serie de particularidades que lo distinguen de los demás subsistemas, las cuales están descritas en el documento base que regula al TBC:

- Se establece preferentemente en instalaciones de las telesecundarias o en espacios que la propia comunidad ponga a disposición del servicio.

- Se imparte en una modalidad escolarizada presencial.

- Se sustenta en el plan de estudios del bachillerato general.

- Cuenta con una plantilla de tres docentes.

- Se apoya en materiales impresos y audiovisuales elaborados expresamente para este servicio.

- La duración de los estudios es mínimo tres años y máximo cinco años (SEMS, 2016). 


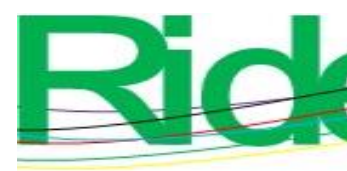

Revista Iberoamericana para la
Investigación y el Desarrollo Educativo
ISSN $2007-7467$

Asimismo, centra su atención en comunidades rurales con menos de 2500 habitantes que no cuentan con otro bachillerato en un radio de cinco kilómetros. El equipamiento básico incluye lo siguiente:

- Un televisor.

- Un proyector de cañón.

- Un reproductor de discos compactos en formato DVD.

- Una laptop para uso de actividades de enseñanza.

En cada plantel laboran tres docentes. Cada uno se enfoca en el área disciplinar que le corresponde de acuerdo con su perfil profesional, el cual se establece en el profesiograma para el telebachillerato comunitario, documento catalogado como "una herramienta de índole académico-administrativo, que contiene de manera organizada y sintética las cualidades o competencias deseables en un profesionista que aspira a ser docente en el telebachillerato comunitario" (Dirección General del Bachillerato, 2019, p. 3).

Los docentes, según el acuerdo secretarial 447, se definen como "el conjunto de educadores que satisfacen los requisitos necesarios y que, como promotores y agentes del proceso educativo, ejercen la docencia a través de la cátedra, la orientación, la tutoría y en general cualquier actividad ligada a estos procesos" (SEMS, 2018, p. 2).

Al iniciar sus operaciones en 2013, el modelo educativo se conformó por el plan y programas de estudio vigentes del bachillerato general con una estructura organizada por asignaturas en tres componentes de formación: básica, propedéutica y profesional. Asimismo, un enfoque intercultural que permite la transversalidad en diversidad, tolerancia y civilidad, que integra también las actividades de tutoría, así como la realización de iniciativas deportivas, artísticas, culturales y de recreación (este plan de estudios estuvo vigente para las primeras cuatro generaciones: 2013-2016; 2014-2017; 2015-2018; 20162019 y 2017-2020.

A partir de 2018, entró en vigor el documento base que sustituye al anterior emitido en 2016, que expresa la finalidad del cambio a plan modular:

Se propone sentar los fundamentos que particularizan al Telebachillerato comunitario como una modalidad escolarizada, presencial que ofrece servicios educativos a poblaciones rurales o en situación de marginalidad preferentemente, o bien en aquellas que teniendo condiciones, no cuenten con cobertura de EMS satisfecha, que tiene como fundamento académico el Plan de Estudios de Bachillerato General de la Dirección General de Bachillerato 


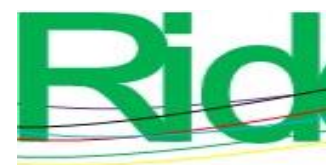

Revista Iberoamericana para la
Investigación y el Desarrollo Educativo
ISSN $2007-7467$

\section{Método}

Existen diversas metodologías para dar seguimiento al egresado. La DGB ha implementado estudios de tipo muestral que permiten tener un panorama nacional; sin embargo, esta tipología no ofrece datos estatales completos y necesarios para tomar decisiones que fortalezcan y mejoren el servicio educativo. Por eso, para contar con la información precisa de cada plantel que integra el servicio educativo en el estado, se consideró la metodología de estudio de casos múltiples, con un enfoque cualitativo y un alcance descriptivo, de tipo censal.

Asimismo, se adopta una perspectiva integradora al estudiar un determinado fenómeno contemporáneo en donde existen diversas circunstancias que al analizarse podrán responder a las preguntas de investigación ligadas prioritariamente al por qué y al cómo. Al examinar el fenómeno con esta metodología se podrá también generar una teoría o, en su caso, contar con un panorama lo suficientemente amplio para asumir alguna postura.

Diversos autores sustentan que el valor del estudio de caso se basa en su oportunidad, lo que implica poder analizar unidades que de otra manera no sería posible. Starke y Strohschneider (2009), citados por Hernández Sampieri, Fernandez y Baptista (2014), señalan que "ofrecen varios beneficios, entre los que se destacan que proporcionan una base de datos enriquecedora e información completa sobre el fenómeno o unidad considerada y revelan diferencias entre expresiones de dicho fenómeno o los casos analizados” (p. 3).

En la tabla 2 se concentran algunas de las principales características de los estudios de caso señalados por Hernández Sampieri et al. (2014): 


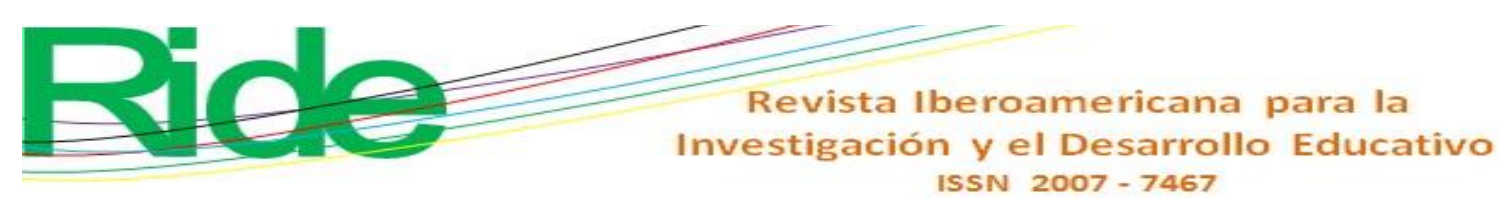

Tabla 2. Características de los estudios de caso

\begin{tabular}{|l|l|}
\hline $\begin{array}{l}\text { Constituyen métodos o diseños flexibles, ya que el } \\
\text { investigador puede utilizar múltiples herramientas } \\
\text { para capturar y analizar los datos que le permiten } \\
\text { comprender las peculiaridades del fenómeno o } \\
\text { problema bajo indagación y conocer sus causas. }\end{array}$ & $\begin{array}{l}\text { Ylossary of the social and } \\
\text { Behavioral Sciences (2009) y } \\
\text { Timmons y Cairns (2009) }\end{array}$ \\
\hline $\begin{array}{l}\text { El investigador y el objeto de investigación } \\
\text { interactúan constantemente entre sí. }\end{array}$ & Aaltio y Heilmann (2009) \\
\hline $\begin{array}{l}\text { El objeto de estudio o caso es examinado de } \\
\text { manera sistémica, global y holística. }\end{array}$ & Xiao (2009) \\
\hline $\begin{array}{l}\text { El investigador casi siempre trata de identificar } \\
\text { patrones. }\end{array}$ & Green (2011) \\
\hline Se realiza en ambientes naturales. & Yin (2013) y Moore (2009) \\
\hline $\begin{array}{l}\text { Son de naturaleza empírica, por lo cual los datos } \\
\text { recolectados deben ser ricos y profundos. }\end{array}$ & $\begin{array}{l}\text { Sekaran y Bougie (2013), Mertler y } \\
\text { Charles (2010) }\end{array}$ \\
\hline $\begin{array}{l}\text { Son completamente contextuales, es decir, } \\
\text { analizan tanto el caso como su contexto, pues } \\
\text { ambos son igualmente importantes. }\end{array}$ & $\begin{array}{l}\text { Hernández Sampieri y Mendoza } \\
\text { (2012) y Stake (2006) }\end{array}$ \\
\hline $\begin{array}{l}\text { Utilizan triangulación de fuentes de datos como eje } \\
\text { de análisis. }\end{array}$ & Greenn (2011) \\
\hline $\begin{array}{l}\text { Se fundamentan en la premisa de que un examen } \\
\text { en profundidad de un caso y su contexto puede } \\
\text { generar información significativa sobre otros casos } \\
\text { similares. }\end{array}$ & $\begin{array}{l}\text { The SAGE Glossary of the Social } \\
\text { and Behavioral Sciencies (2009) }\end{array}$ \\
\hline $\begin{array}{l}\text { Incluyen todas las perspectivas posibles de los } \\
\text { participantes. }\end{array}$ & Rauffler (2009) \\
\hline
\end{tabular}

Fuente: Hernández Sampieri et al. (2014)

Dentro de esta recopilación de características se aprecia la gran utilidad de los estudios de caso que permiten de forma integral y holística estudiar un fenómeno en un ambiente natural con el propósito de recabar información significativa y poder establecer patrones.

En este sentido, al estudiar el servicio educativo telebachillerato comunitario del estado de Campeche se pretende identificar patrones que permitan comprender cómo ha respondido dicho servicio a las necesidades de la comunidad y formación de estudiantes de tal manera que puedan generar propuestas de mejora de su entorno y calidad de vida. En este proceso se consideran como más importantes las preguntas cómo y por qué, ya que el investigador no tiene gran control sobre el fenómeno estudiado. Yin (1994) define el estudio de caso de la siguiente manera: 


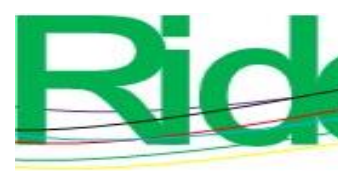

Revista Iberoamericana para la Investigación y el Desarrollo Educativo ISSN $2007-7467$

Un estudio de caso es (1) una pregunta empírica que investiga un fenómeno contemporáneo dentro de su contexto de vida real sobre todo cuando los límites entre el fenómeno y contexto no son claramente evidentes, (2) la pregunta de estudio de caso cubre con la técnicamente distintiva situación en la cual habrá muchas más variables de interés que apuntes de datos y como resultado confía en las fuentes múltiples de evidencia, con datos que necesitan converger en una moda triangular, y como resultado beneficia el desarrollo anterior de proposiciones teóricas para guiar la colección de los datos y análisis (p. 9).

Cada investigación debe basarse en un plan que será la guía del investigador; de este modo, se contará con un método para recolectar y analizar la información que se recaba, la cual luego se usará para emitir un informe. Según Yin (1994), los componentes de un plan de investigación para los estudios de caso son cinco:

- Una pregunta de estudio.

- Sus proposiciones, si hubiera.

- Su unidad o unidades de análisis.

- La lógica que une los datos a las proposiciones.

- Criterio para interpretar los resultados de un estudio.

Para la recolección de datos se diseñó una encuesta que se aplicó a dos grupos poblaciones: los alumnos de sexto semestre (previo a su egreso en el momento del estudio) y los egresados de años anteriores (de los cuales no se contaba con registro).

El estudio - al tener la finalidad de realizar comparaciones y establecer patronesnecesita recabar información desde todos los ángulos posibles. Por eso —y para no limitarlo a una sola zona donde tres o cuatro planteles estuvieran en condiciones similares, pero que no se aplicaran para los restantes_-, se decidió que cada plantel se considerara un caso. Esto permite tener una visión general y analizar aspectos centrales de cada plantel para establecer semejanzas y diferencias. En concreto, cada caso se identificó con el nombre del plantel (en total fueron 19): 


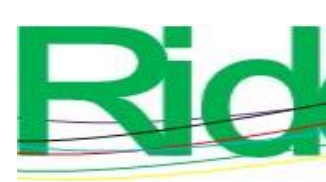

Revista Iberoamericana para la Investigación y el Desarrollo Educativo ISSN $2007-7467$

Tabla 3. Casos definidos para el estudio

\begin{tabular}{|l|l|}
\hline N. ${ }^{\circ}$ de caso & Nombre del caso \\
\hline Caso 1 & Adolfo Ruiz Cortínez \\
\hline Caso 2 & Carlos Salinas de Gortari \\
\hline Caso 3 & Chunchintok \\
\hline Caso 4 & Chunkanan \\
\hline Caso 5 & Cumpich \\
\hline Caso 6 & Gustavo Díaz Ordaz \\
\hline Caso 7 & Isla Arena \\
\hline Caso 8 & Iturbide \\
\hline Caso 9 & La Victoria \\
\hline Caso 10 & Laguna Grande \\
\hline Caso 11 & Mancolona \\
\hline Caso 12 & Miguel Colorado \\
\hline Caso 13 & Nayarit Castellot \\
\hline Caso 14 & Oxcabal \\
\hline Caso 15 & Pablo García \\
\hline Caso 16 & San José de las Montañas \\
\hline Caso 17 & Suctuc \\
\hline Caso 18 & Tikinmul \\
\hline Caso 19 & Yohaltun \\
\hline
\end{tabular}

Fuente: Elaboración propia

El diseño de múltiples casos es particularmente útil, dado que permitirá encontrar las similitudes y diferencias entre cada uno de ellos para poder establecer patrones y generar el reporte comparativo. El estudio se llevó a cabo utilizando la lógica de repetición sobre la de muestreo, ya que se analizaron la totalidad de los planteles en un periodo de 8 meses (desde abril a noviembre de 2019).

La primera fase del estudio se enfocó en la población que ya egresó (generaciones 2013, 2014 y 2015). El propósito fue conocer lo que están haciendo estas personas (el rumbo profesional y personal que han tomado). La segunda fase del estudio se centró en la población que en el momento del estudio estaba próxima a egresar (generación 2016-2019) con el fin de dar continuidad al estudio de la primera fase (esto se hará con cada generación subsecuentemente).

Se tomaron los meses de abril, mayo y junio de 2019 para la aplicación del instrumento que se realizó por medio de formularios de Google. La información que se recabó por cada egresado fue de qué plantel egresó, en qué año y datos generales como nombre, sexo, correo electrónico, edad, estado civil, hijos, ocupación, instituciones en que se encuentran matriculados, así como en qué áreas se desenvuelven profesionalmente. Finalmente, se procuró saber el grado de satisfacción de la formación recibida en el telebachillerato comunitario. 

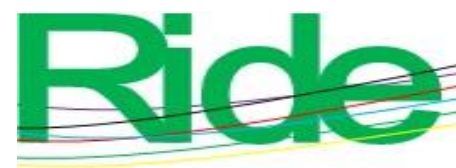

Revista Iberoamericana para la Investigación y el Desarrollo Educativo

ISSN $2007-7467$

Para la segunda fase se consideró a los estudiantes que estaban próximos a egresar en el mes de julio de 2019 (el periodo de registro finalizó en el mes de noviembre de 2019). En esta fase el propósito fue reconocer las expectativas en torno a su proyecto de vida profesional y laboral, y si lograron llevarlo a cabo. Dado que el periodo de recolección de datos culminó en noviembre, se pudieron registrar los resultados de sus postulaciones a instituciones de educación superior o si se lograron insertar al campo laboral.

\section{Resultados}

A continuación, se presentan los resultados obtenidos. Se registraron en total 516 egresados distribuidos por generaciones de la siguiente manera:

Figura 1. Número de egresados de TBC por generación

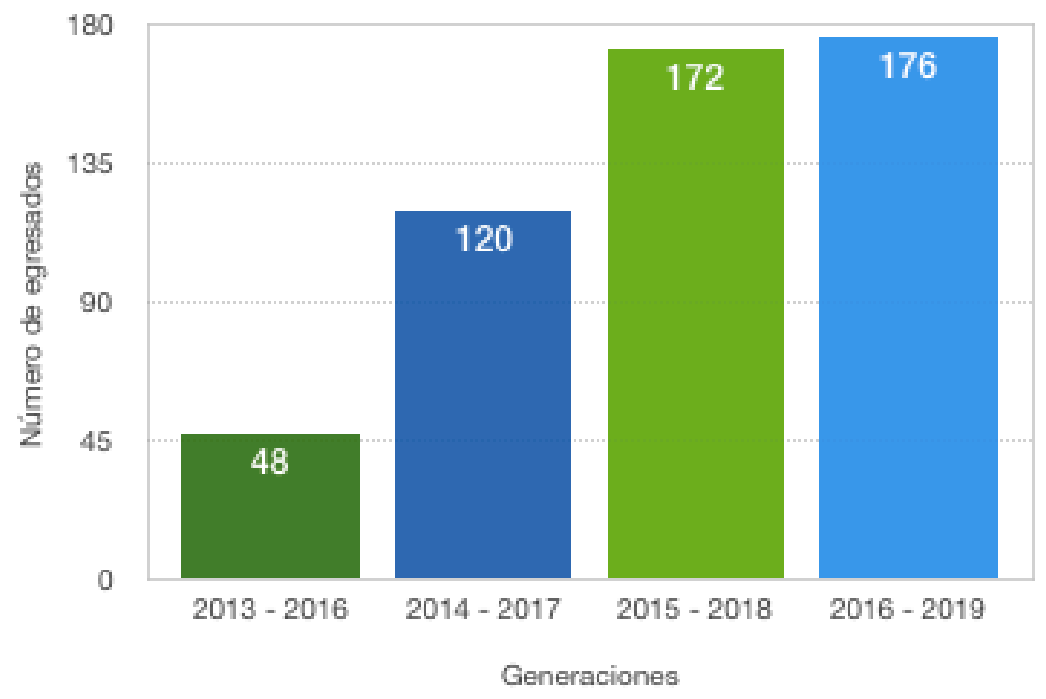

Fuente: Elaboración propia

Es importante destacar que se registra un crecimiento de $336 \%$ porque, como ya se mencionó, a partir del año 2013 hubo un incremento progresivo de TBC, los cuales en la actualidad suman 19 centros (figura 2). 

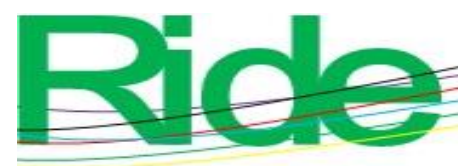

Revista Iberoamericana para la Investigación y el Desarrollo Educativo ISSN $2007-7467$

Figura 2. Planteles que tuvieron egreso en cada generación

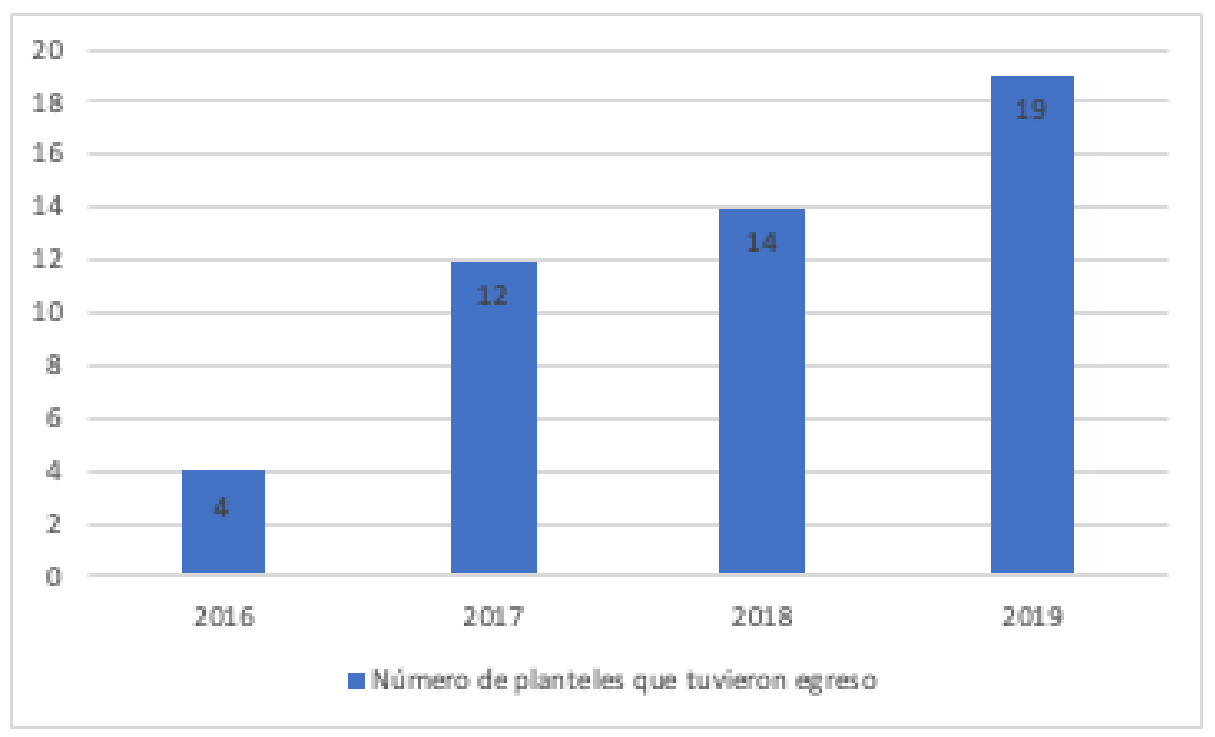

Fuente: Elaboración propia

En relación con el género, de los 516 egresados, 54 \% son hombres y $45.93 \%$ mujeres (figura 3).

Figura 3. Egresados por sexo y generación

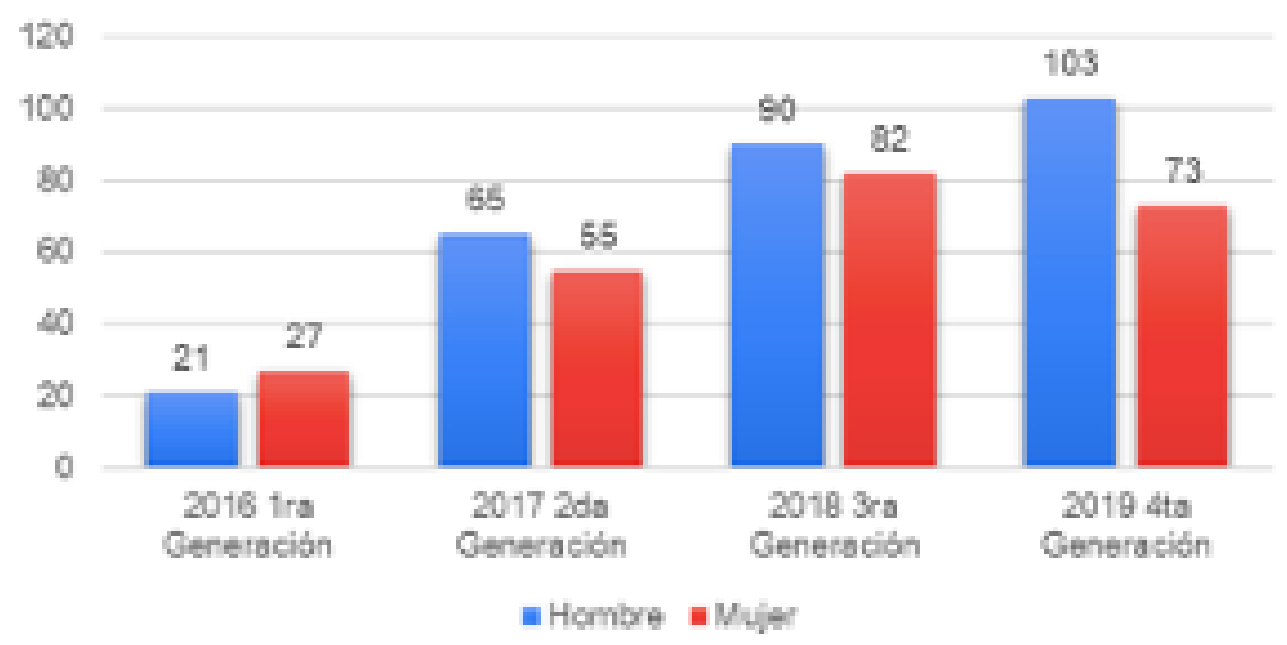

Fuente: Elaboración propia

En relación con el número de egresados de cada plantel, en la figura 4 se puede observar que el mayor número en un plantel de TBC Campeche fue de 65 (Mancolona) y el menor número fue 2 en los planteles de Adolfo Ruiz Cortínez y Gustavo Díaz Ordaz. 

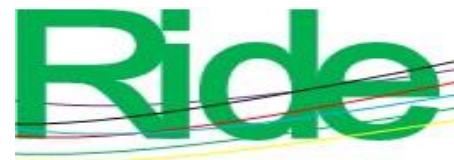

Revista Iberoamericana para la Investigación y el Desarrollo Educativo ISSN 2007 - 7467

Figura 4. Número de egresos en cada plantel de TBC Campeche

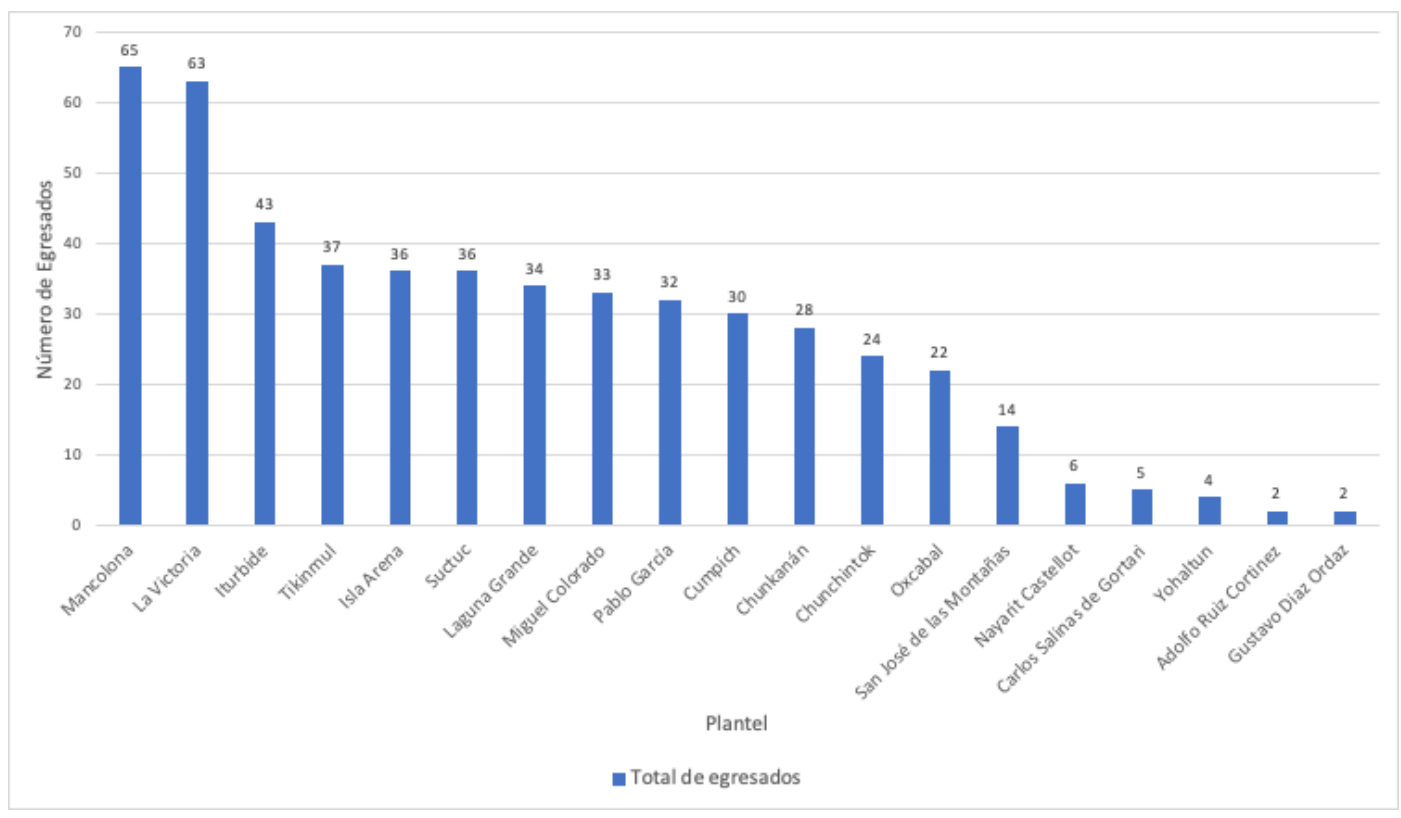

Fuente: Elaboración propia

En la figura 5 se observa que de los 516 egresados, $139(26.93 \%)$ se encuentran estudiando, de los cuales $56 \%$ son hombres y $36.69 \%$ mujeres.

Figura 5. Egresados que se encuentran estudiando

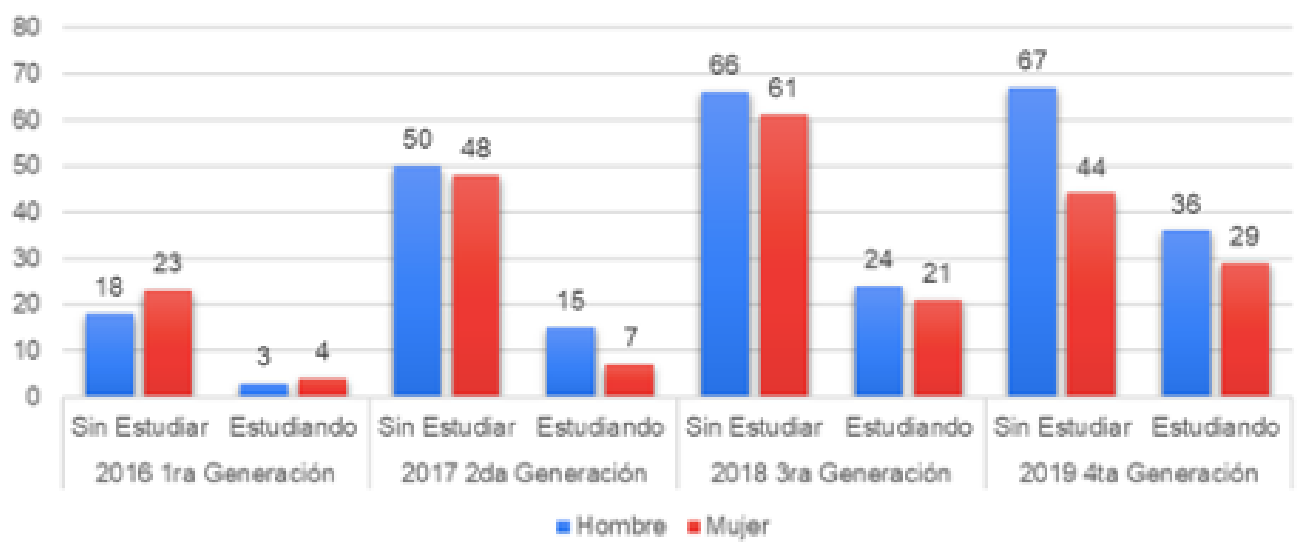

Fuente: Elaboración propia

En cuanto al nivel de estudio en que se encuentran matriculados, $86 \%$ se hallan estudiando en instituciones de nivel superior, mientras que $9 \%$ se encuentran estudiando nivel técnico o algún oficio (5\% no especificó). 

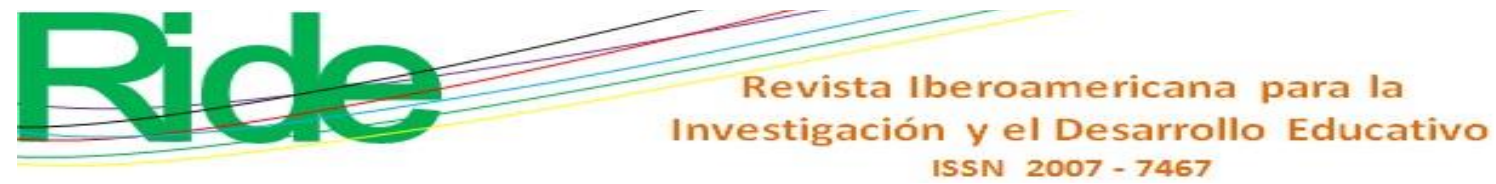

Figura 6. Nivel educativo en que se matricularon los egresados

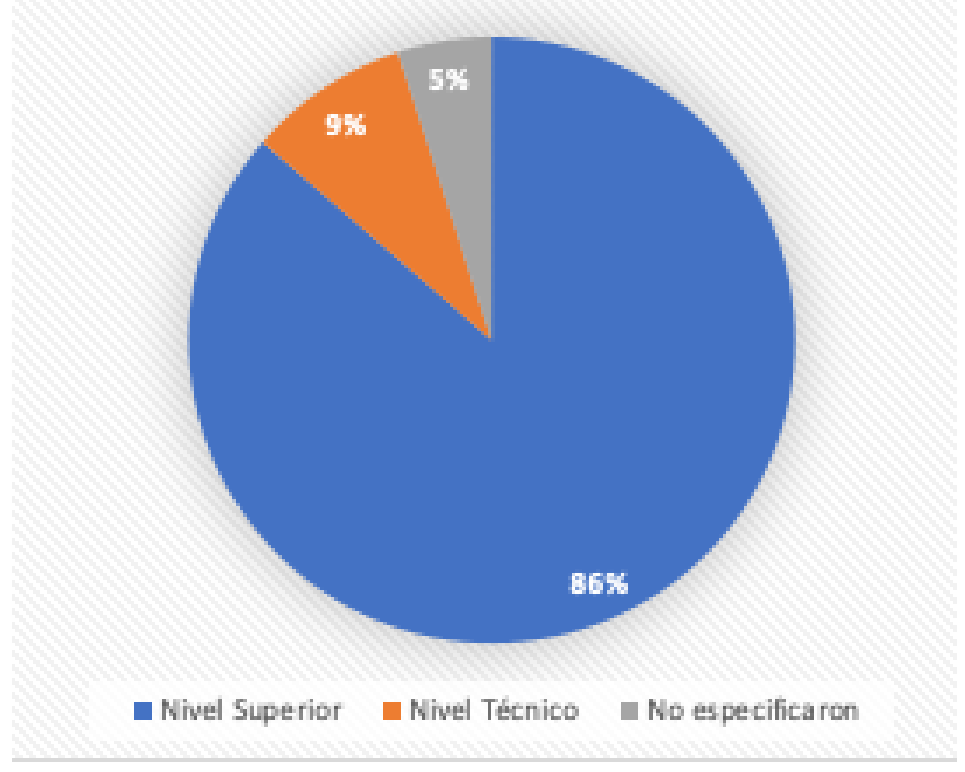

Fuente: Elaboración propia

Con respecto a las principales carreras elegidas por los egresados, $62 \%$ se encuentran estudiando licenciatura en Administración de Empresas, 7 \% ingeniería en Innovación Agrícola Sustentable, $6 \%$ ingeniería en Sistemas Computacionales, $4 \%$ Contabilidad (en otras carreras se encuentra matriculado el equivale a $2 \%$ ).

Figura 7. Principales carreras elegidas por los egresados

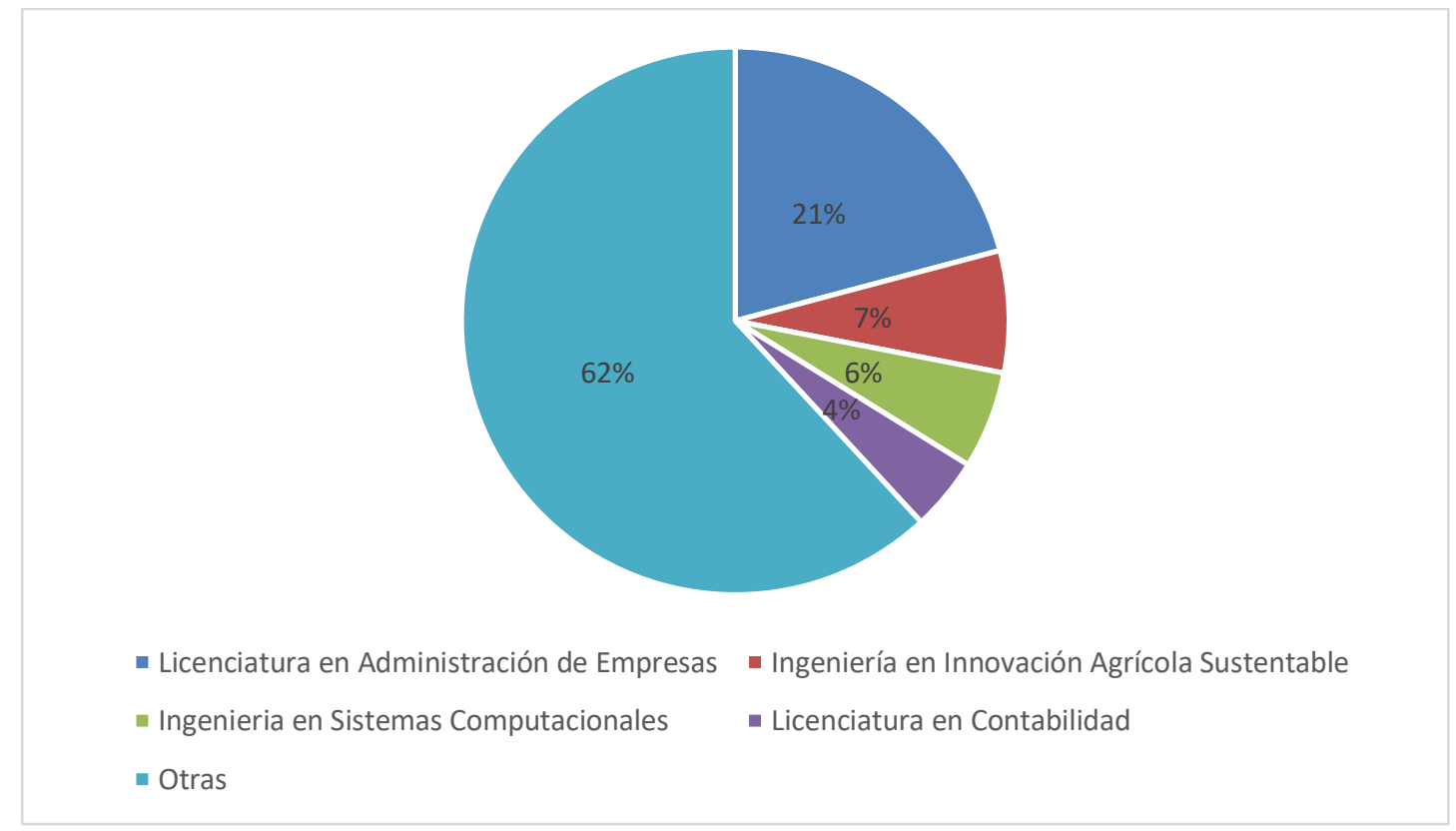

Fuente: Elaboración propia 

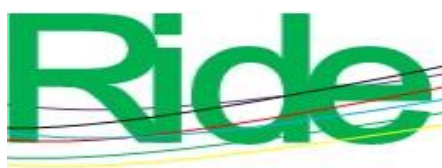

Revista Iberoamericana para la Investigación y el Desarrollo Educativo

ISSN 2007 - 7467

En relación con la situación laboral, $61.24 \%$ de los egresados se encuentra laborando, de los cuales $40 \%$ son hombres y $20 \%$ mujeres.

Figura 8. Situación laboral de egresados

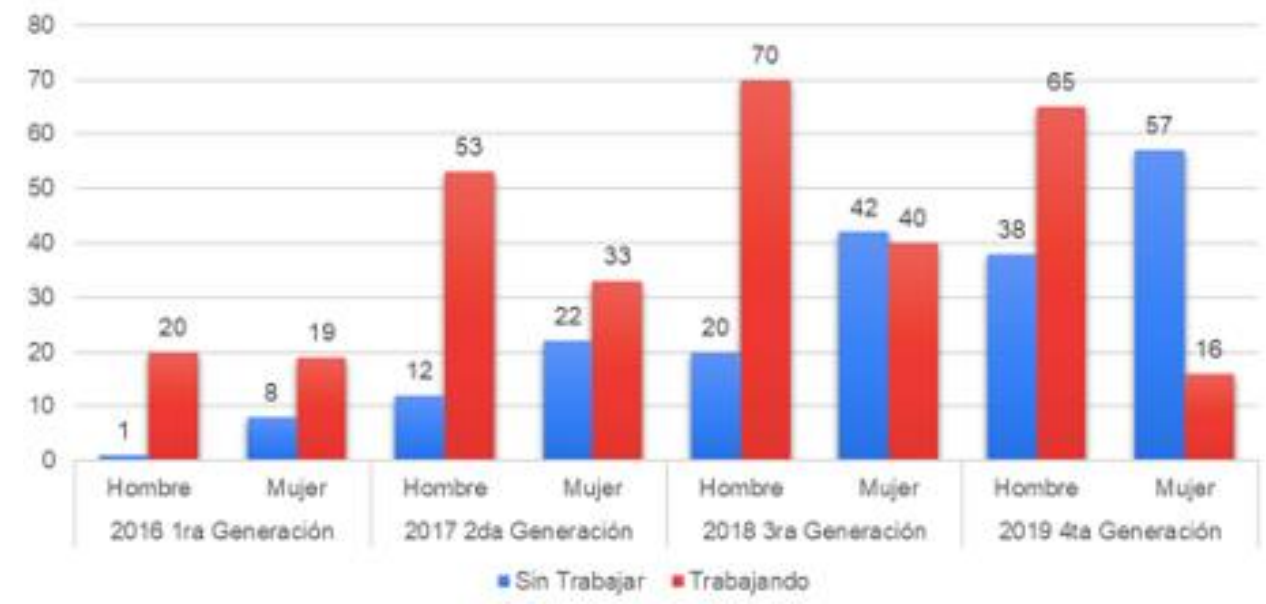

Fuente: Elaboración propia

Sobre el tipo de trabajo que desempeñan, las principales actividades se pueden apreciar en la tabla 4, donde se destacan las labores del campo y de la casa.

Tabla 4. Principales actividades laborales

\begin{tabular}{|l|c|}
\hline Actividades laborales & Número de egresados \\
\hline Labores domésticas & 39 \\
\hline $\begin{array}{l}\text { Asistente en la comisaría } \\
\text { municipal }\end{array}$ & 1 \\
\hline Independiente & 49 \\
\hline Labores de limpieza & 1 \\
\hline Labores del campo & 99 \\
\hline Labores del campo, independiente & 4 \\
\hline Privado & 54 \\
\hline Privado, independiente & 1 \\
\hline Privado, labores del campo & 1 \\
\hline Público & 37 \\
\hline Público, labores del campo & 1 \\
\hline Secretaría de la defensa nacional & 2 \\
\hline N/E & 27 \\
\hline Total & 316 \\
\hline
\end{tabular}

Fuente: Elaboración propia 


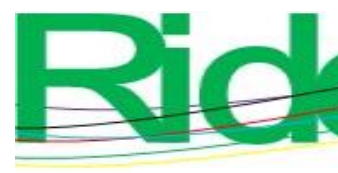

Revista Iberoamericana para la Investigación y el Desarrollo Educativo ISSN $2007-7467$

En relación con el grado de satisfacción de la formación recibida en el TBC, para 42 $\%$ de los egresados fue una experiencia de formación muy satisfactoria, 38\% la consideró satisfactoria, $10 \%$ aceptable y $10 \%$ omitió su opinión.

Figura 9. Nivel de satisfacción de la formación recibida

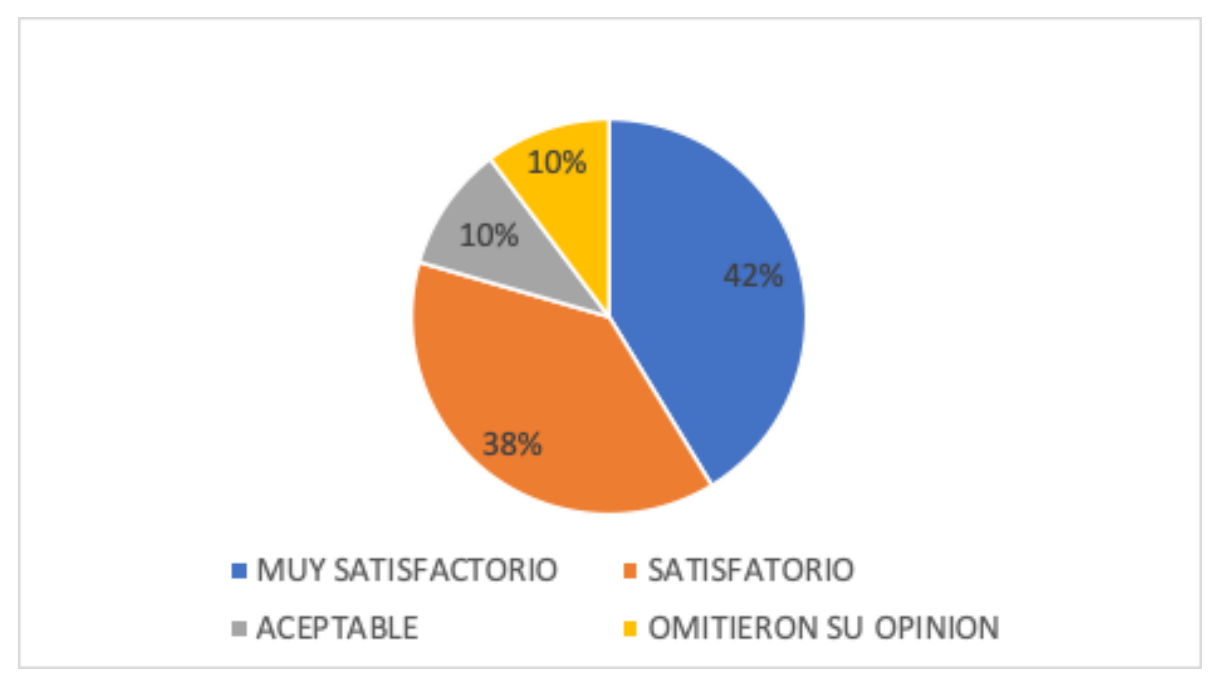

Fuente: Elaboración propia

\section{Discusión}

Los resultados obtenidos permiten dar respuesta a la pregunta de investigación planteada al inicio del estudio, es decir, ¿cuál es la trayectoria que han seguido los egresados del telebachillerato comunitario en el estado de Campeche? En tal sentido, al comparar los resultados de cada plantel, se registraron porcentajes similares de hombres y mujeres que culminaron sus estudios de nivel medio superior en el telebachillerato, lo que evidencia la posibilidad de un desarrollo académico equitativo. Esta es una gran fortaleza percibida.

Uno de los propósitos fundamentales de la EMS es dotar al estudiante de las competencias necesarias para continuar sus estudios de nivel superior. Seguir este trayecto se traduce en un proyecto de vida profesional y una visión para labrarse un futuro mejor. Al respecto, se puede indicar que $26 \%$ se encuentra estudiando actualmente alguna carrera, en especial licenciatura en Administración de Empresas. En un futuro trabajo se podría indagar en las razones de esta elección. Sin embargo, también se debe señalar que la mayoría ha optado por trabajar. Si bien las condiciones socioeconómicas pueden dificultar la continuidad de los estudios, se percibe como necesario incluir en futuras investigaciones este aspecto. En el TBC la formación profesional se promueve para impulsar el desarrollo de competencias encaminadas a lograr en el estudiante actitudes responsables hacia su entorno. En otras 


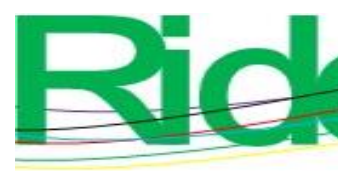

Revista Iberoamericana para la Investigación y el Desarrollo Educativo ISSN $2007-7467$

palabras, los egresados al contar con esta formación están capacitados para laborar en organizaciones civiles, ofreciendo servicios de orientación, trabajo social, encuestas de opinión pública, investigación, capacitación, etc.

Asimismo, se debe indicar que la ocupación principal de los egresados que no continuaron sus estudios son las labores de campo y domésticas, por lo que resulta prioritario para el servicio educativo fortalecer esta capacitación. Queda como una tarea pendiente para los profesionales de la educación implementar estrategias que permitan la consolidación y continuidad de los proyectos para convertirlos en una actividad permanente y benéfica, que aporte elementos de autosuficiencia en caso de optar por quedarse con este nivel educativo.

Dado que se espera que los egresados estén preparados para continuar sus estudios en el nivel superior inmediato, así como que incidan positivamente en su comunidad aprovechando la formación de capacitación para el trabajo, este aspecto aún sigue siendo un área de debilidad importante.

Por otra parte, se debe subrayar que fue particularmente difícil contactar a los egresados, dado que no había un registro previo de ellos. Por eso, al no contar con una base de datos institucional, se diseñó un formulario que fue llenado en su mayoría por el personal de los planteles que colaboraron en la tarea de ubicación de los egresados. Esta, por una parte, fue una de las principales fortalezas de este trabajo, pues se la suma de esfuerzos de la comunidad educativa sirvió para localizar y registrar al mayor número de egresados. Sin embargo, al mismo tiempo, esta fue una de las áreas de debilidad de este trabajo, por lo que para generaciones posteriores se sugiere implementar mecanismos que faciliten la comunicación y seguimiento de los alumnos, así como diseñar un proceso más estandarizado y sistematizado que garantice la emisión de resultados fiables.

Asimismo, incrementar el número de estudiantes que ingresan al nivel superior sigue siendo uno de los principales retos del telebachillerato comunitario, así como fortalecer el trabajo por proyectos para incidir directamente en la comunidad y para que permanezcan activos aun después de haber egresado.

Los resultados, en síntesis, permiten reafirmar la necesidad de fortalecer la calidad de la educación media superior, sobre todo la que se imparte en las poblaciones más vulnerables. Igualmente, se deben proveer los insumos suficientes para que las decisiones que se tomen puedan incidir favorablemente en las realidades de los jóvenes. 


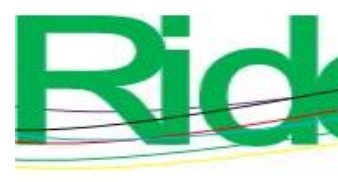

Revista Iberoamericana para la Investigación y el Desarrollo Educativo ISSN $2007-7467$

\section{Conclusiones}

El presente estudio sirvió para ofrecer insumos valiosos sobre cómo el servicio educativo telebachillerato comunitario en el estado de Campeche ha ido consolidándose como una oferta educativa que ofrece a los jóvenes educación de calidad, de ahí que en la actualidad sea reconocida como una alternativa para formarse de manera académica. Esta consolidación ha permitido que sea el segundo servicio educativo más grande en el estado, con 19 planteles distribuidos en el interior. Asimismo, el crecimiento sostenido de su matrícula ha hecho que se atienda a una población de 800 alumnos que pueden recibir educación media superior.

El incremento en la matrícula refleja que en el TBC se realizan estudios de nivel medio superior en donde hombres y mujeres desarrollan de la misma manera las competencias requeridas, lo que resulta sumamente motivador, dado los esfuerzos de los docentes para evitar que las mujeres abandonen los estudios para asumir roles tradicionales (amas de casa) dentro de la comunidad.

Valorar la importancia de realizar este estudio representó un esfuerzo para que se genere en cada plantel una cultura de seguimiento al egresado como base para la mejora, por lo que su continuidad será fundamental para fortalecer la educación que se imparte.

Al egresar, se espera que los jóvenes den muestra de sus capacidades y de su integración en todos los ámbitos de la sociedad y los relacionados con su formación integral (aspectos físicos, afectivos, sociales).

En cuanto al número de estudiantes que lograron egresar satisfactoriamente, de las cuatro generaciones analizadas se registraron 516; en futuras investigaciones se contemplará el análisis de la eficiencia terminal.

Siendo uno de los propósitos del servicio educativo orientar el interés vocacional de los jóvenes y que continúen sus estudios, al registrar que de los 139 egresados que estaban estudiando en el momento de aplicar la encuesta, 120 lo hacen en instituciones de educación superior, se puede afirmar que la primera opción de estudio es el nivel superior (muy por debajo se hallan las carreras técnicas u oficios).

Un aspecto que es necesario fortalecer es el relacionado con la ocupación. En este sentido, $61.24 \%$ de los egresados se encuentra laborando al momento del estudio, de los cuales $40 \%$ son hombres y $20 \%$ mujeres. Sin embargo, las ocupaciones distan mucho del propósito del autoempleo, el empleo formal o el relacionado con su formación profesional (es decir, trabajo comunitario), ya que prioritariamente laboran en el campo o en el hogar. 


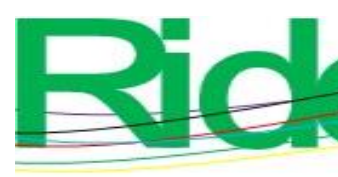

Revista Iberoamericana para la
Investigación y el Desarrollo Educativo
ISSN $2007-7467$

Reconocer la trayectoria del egresado es parte fundamental de la evaluación educativa y curricular, pues sirve para valorar la pertinencia de los planes de estudio y el logro de competencias que caracterizan a la educación media superior.

Con los resultados, cada plantel contará con datos que permitan valorar las fortalezas y debilidades de sus centros educativos, analizar los aspectos relacionados con el rendimiento de los estudiantes, así como realizar evaluaciones educativas en todos sus ámbitos teniendo en cuenta que el centro escolar, la administración educativa y los procesos de enseñanza y aprendizaje deben estar en concordancia para la consecución de los objetivos.

\section{Futuras líneas de investigación}

El presente estudio pone de manifiesto la necesidad de continuar documentando e investigando sobre los diversos actores y procesos del servicio educativo telebachillerato comunitario, como futuras líneas de investigación se mencionan las siguientes:

- Continuidad al seguimiento de egresados para mantener el historial actualizado que permita contar con insumos sobre la trayectoria que siguen los jóvenes al egresar.

- Analizar la eficiencia terminal para conocer la cantidad de jóvenes que egresan comparándolo con los de nuevo ingreso.

- Un siguiente aspecto es profundizar en la evaluación externa del curriculum para documentar la experiencia que han tenido los egresados en las ocupaciones formales e informales en las que se desempeñan recabando la percepción de los empleadores.

- Dar seguimiento a la trayectoria profesional del egresado, para reconocer las áreas disciplinares en las que se siente fortalecido y aquellas que se le han dificultado en su formación superior.

Finalmente, se percibe como necesario incluir de forma permanente en el trabajo colegiado estudios no solo de egresados, sino de todos los procesos relacionados con la formación de los estudiantes para concretar acciones encaminadas al fortalecimiento de la educación en Campeche y, sobre todo, brindar a jóvenes que se encuentran en situación vulnerable posibilidades de superación. 


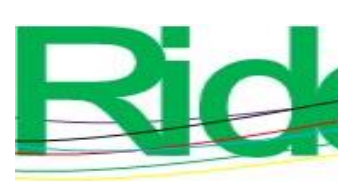

Revista Iberoamericana para la Investigación y el Desarrollo Educativo ISSN 2007-7467

\section{Referencias}

Alanís, J. F. (2020). Egresados de telebachillerato comunitario y su capacidad de aspiración. Revista Latinoamericana de Estudios Educativos, 50(2), 165-194. Recuperado de https://www.redalyc.org/articulo.oa?id=270/27062001005

Barriga, F. D., González, M., Pacheco Pinzón, D., Saad Dayan, E. y Rojas Drummond, S. (1990). Metodología del diseño curricular. México: Trillas.

DGB (2019). Profesiograma para el telebachillerato comunitario por área disciplinar. Recuperado de https://www.dgb.sep.gob.mx/servicioseducativos/telebachillerato/normatividad/Profesiograma-2-19-Actualizacion.pdf

Diario Oficial de la Federación (2019). Decreto por el que se expide la Ley General de Educación y se abroga la Ley General de la Infraestructura Física Educativa. Recuperado de https://www.dof.gob.mx/nota_detalle.php?codigo=5573858\&fecha=30/09/2019\&pr int=true

Diario Oficial de la Federación (2019). Por el que se expide la Ley General de Educación y se abroga la Ley General de la Infraestructura Física y Educativa. 30 Septiembre de 2019. Recuperado de https://www.dof.gob.mx/nota_detalle.php?codigo=5573858\&fecha=30/09/2019\&pr int $=$ true

García, R. S., Fonseca Bautista, C. D. e Ibarra Uribe, L. M. (2017). Seguimiento de egresados en educación media superior. Una tarea pendiente y necesaria. Trabajo presentado en el Congreso Nacional de Investigación Educativa COMIE. San Luis Potosí, México.

Recuperado de https://www.comie.org.mx/congreso/memoriaelectronica/v14/doc/0645.pdf

Hernández Sampieri, R. H., Fernández, C. C. y Baptista, L. P. (2014). Metodología de la investigación. México: Mc Graw Hill.

Instituto Nacional para la Evaluación de la Educación [INEE] (2018a). Educación media superior: los desafíos. Revista de Evaluación para Docentes y Directivos, 9, 5. Recuperado de https://www.inee.edu.mx/wp-content/uploads/2018/12/Red09.pdf

Instituto Nacional para la Evaluación de la Educación [INEE] (2018b). Principales cifras. Educación básica y media superior. Inicio del ciclo escolar 2017-2018. México. Recuperado de https://www.inee.edu.mx/wp-content/uploads/2019/01/P2M109.pdf 


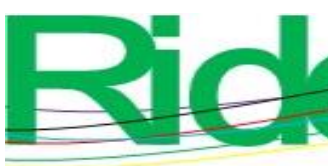

Revista Iberoamericana para la
Investigación y el Desarrollo Educativo
ISSN $2007-7467$

Instituto Tecnológico de Estudios Superiores de Monterrey [ITESM] (2006). Manual de instrumentos y recomendaciones sobre el seguimiento de egresados. Red Gradua2 / $\begin{array}{llll}\text { Asociación } & \text { Columbus. } & \text { Recuperado }\end{array}$ https://www.almalaurea.it/sites/almalaurea.it/files/docs/universita/altro/red_gradua2 .pdf

Ramírez, C. G. y Padilla González, L. E. (2017). El telebachillerato comunitario en Aguascalientes: estudio de un caso de alta eficacia escolar. Trabajo presentado en el Congreso Nacional de Investigación Educativa COMIE. San Luis Potosí, México. Recuperado de http://www.comie.org.mx/congreso/memoriaelectronica/v14/doc/2246.pdf

Subsecretaría de Educación Media Superior [SEMS] (2008). Acuerdo 447 por el que se establecen las competencias docentes para quienes impartan educación media superior en la modalidad escolarizada. México: Autor. Recuperado de: http://bit.ly/2vW3jyF

Subsecretaría de Educación Media Superior [SEMS] (2016). Documento base del telebachillerato comunitario. México.

Subsecretaría de Educación Media Superior [SEMS] (2018). Documento base del telebachillerato comunitario (2. ${ }^{\mathrm{a}}$ ed.). México. Recuperado de https://www.dgb.sep.gob.mx/servicioseducativos/telebachillerato/normatividad/Documento-base-2018.pdf

Subsecretaría de Educación Media Superior [SEMS] (2020). Educación Media Superior. Recuperado de http://www.sems.gob.mx/work/models/sems/Resource/12491/4/images/Educacion\% 20Media\%20Superior.pdf

Yin, R. K. (1994). Investigación sobre estudio de casos (2. ${ }^{a}$ ed.). London: Publicaciones SAGE. Recuperado de https://panel.inkuba.com/sites/2/archivos/YIN\%20ROBERT\%20.pdf 